\title{
Mitral valve repair for advanced myxomatous degeneration with posterior displacement of the mitral annulus
}

Andrew E. Newcomb, FRACS, Tirone E. David, MD, Vidyadhar S. Lad, FRCS, Jerzy Bobiarski, MD, Susan Armstrong, MSc, and Manjula Maganti, MSc

Objective: This study examines the outcomes of mitral valve repair in a defined group of patients with mitral regurgitation caused by advanced myxomatous degeneration.

Methods: Advanced myxomatous degeneration of the mitral valve was defined as a degenerative process whereby both leaflets are voluminous and aneurysmal and the mitral annulus diameter exceeds $40 \mathrm{~mm}$ and has posterior displacement, as determined by means of echocardiographic analysis. Over a 16-year period, we identified 183 patients who underwent valve repair in this subgroup of myxomatous degeneration. The repair consisted of relocating the posterior mitral annulus to the endocardium of the left ventricle at the atrioventricular junction, correction of leaflet prolapse, and annuloplasty. Analysis of perioperative variables and postoperative outcomes were undertaken. The mean follow-up was $5.9 \pm 4.2$ years and complete.

Results: The patients' mean age was 52 years, and 118 were men. All patients had mitral regurgitation preoperatively. There were no early and only 8 late deaths (2 valve-related deaths). The survival at 10 years was $92 \% \pm$ $3 \%$. Six patients required reoperation on the mitral valve, 5 for recurrent severe mitral regurgitation. The freedom from reoperation at 10 years was $93 \% \pm 3 \%$. Six patients had severe and 21 had moderate mitral regurgitation. The freedom from recurrent moderate or severe mitral regurgitation at 10 years was $80 \% \pm 5 \%$. We could not identify independent predictors of recurrent mitral regurgitation.

Conclusions: Mitral valve repair for advanced myxomatous degeneration on the mitral valve provides excellent early functional results, but late recurrent regurgitation is common, despite correction of dilated and displaced mitral annulus and leaflet prolapse.

Carpentier and associates ${ }^{1}$ described myxomatous degeneration and fibroelastic deficiency as 2 distinct degenerative disorders that can cause mitral valve leaflet prolapse and mitral regurgitation (MR). The pathologic spectrum of one of these entities, the myxomatous degeneration of the mitral valve, varies widely and does not necessarily correlate well with the severity of mitral valve dysfunction. Thus myxomatous degeneration can be limited to a single segment of the mitral valve and associated with severe MR, whereas advanced myxomatous degeneration involving all segments of the mitral valve can be associated with only mild MR. However, patients with advanced myxomatous degeneration of the mitral valve might also have severe MR that requires surgical attention. Mitral valve repair is difficult because the degenerative process involves the mitral annulus, the leaflets, the chordae tendineae, and sometimes even the papillary muscles., ${ }^{2,3}$ The posterior mitral annulus in patients with advanced myxomatous degeneration is often posteriorly displaced, as described by Hutchins and col-

\footnotetext{
From the Division of Cardiovascular Surgery of the Peter Munk Cardiac Centre at the Toronto General Hospital, University Health Network and University of Toronto, Toronto, Ontario, Canada.

Received for publication Feb 29, 2008; revisions received May 4, 2008; accepted for publication May 20, 2008

Address for reprints: Tirone E. David, MD, 200 Elizabeth St-4N457, Toronto, Ontario M5G 2C4, Canada (E-mail: tirone.david@uhn.on.ca).

J Thorac Cardiovasc Surg 2008;136:1503-9

$0022-5223 / \$ 34.00$

Copyright (C) 2008 by The American Association for Thoracic Surgery

doi:10.1016/j.jtcvs.2008.05.059
}

leagues. ${ }^{4}$ The leaflets in advanced myxomatous degeneration are voluminous and aneurysmal, and the number of prolapsing segments is proportional to the degree of displacement of the mitral annulus. ${ }^{5}$ Some surgeons refer to this entity as "Barlow's disease", in honor of John Barlow, who first described "aneurysmal protrusion" of the posterior leaflet of the mitral valve. ${ }^{6}$

Prolapse of the central scallop of the posterior leaflet is the most common lesion among patients referred for surgical intervention for MR. ${ }^{7}$ However, in surgical series in which mitral valve repair rates exceed $90 \%$ of all patients with degenerative disease of the mitral valve, the incidence of bileaflet prolapse is fairly high. ${ }^{7}$ In our experience the most common cause of bileaflet prolapse is advanced myxomatous degeneration of the mitral valve.

In this study we defined advanced myxomatous degeneration of the mitral valve and reviewed the clinical outcomes of mitral valve repair in this subgroup of patients with MR.

\section{MATERIALS AND METHODS}

From August 1990 to November 2006, one of us (TED) operated on 1032 patients for isolated MR caused by degenerative disease of the mitral valve at the Peter Munk Cardiac Centre. The clinical profile, echocardiographic data, surgical pathology, and technique of repair were collected prospectively and entered into a database. Carpentier's classification was used to describe the various segments of leaflet prolapse. ${ }^{8}$

Based on the results of intraoperative transesophageal echocardiography (TEE), the degree of myxomatous changes (graded as mild, moderate, and severe depending on the size and thickness of the leaflets), the prolapsing segments, the systolic diameter of the mitral annulus measured by a $0^{\circ}$, 


$$
\begin{aligned}
& \text { Abbreviations and Acronyms } \\
& \qquad \begin{aligned}
\text { ePTFE } & =\text { expanded polytetrafluoroethylene } \\
\text { MR } & =\text { mitral regurgitation } \\
\text { TEE } & =\text { transesophageal echocardiography }
\end{aligned}
\end{aligned}
$$

and the severity of MR was recorded. ${ }^{5,9}$ For the purpose of this study, advanced myxomatous degeneration of the mitral valve was defined as a degenerative process whereby both leaflets were thickened $(\geq 3 \mathrm{~mm})$, voluminous, and aneurysmal; the mitral annulus diameter in systole was $40 \mathrm{~mm}$ or larger; and there was at least $5 \mathrm{~mm}$ of posterior displacement of the mitral annulus, as determined by means of TEE analysis (Figure 1) and verified at surgical intervention. The degree of annular displacement was measured at the P2 level by using a 4-chamber midesophageal view at $0^{\circ}$ during systole. ${ }^{5,9}$

Of 1032 patients with degenerative mitral valve disease, mitral valve repair was performed in $943(91 \%)$, and replacement in 89 (9\%). Advanced myxomatous changes, extensive calcification of the mitral annulus, and active infective endocarditis were the main reasons for mitral valve replacement. Advanced myxomatous degeneration of the mitral valve was present in 211 patients, and mitral valve repair was performed in 183 $(86 \%)$ patients. Five patients had repairs attempted, but the valve was replaced at the same operation without serious perioperative complications. Preoperative and perioperative characteristics of all patients who had mitral valve repair for advanced myxomatous degeneration are shown in Tables 1 and 2. Our institutional research ethics board approved this study.

\section{Operative Technique}

Operations were carried out after achievement of general anesthesia with cardiopulmonary bypass and mild hypothermia $\left(34^{\circ} \mathrm{C}\right)$. Myocardial protection was provided by means of intermittent antegrade cold blood cardioplegia. The mitral valve was exposed though a generous left atriotomy along the interatrial groove, dome, and posterior wall of the left atrium. The entire posterior leaflet was detached from its insertion in 154 patients and along P2 and $\mathrm{P} 3$ in 29 patients (Figure 2). Multiple interrupted 2-0 polyester sutures were passed through the endocardium of the posterior wall of the left ventricle, where the mitral annulus was supposed to be, and also through the tissue between the ventricle and the displaced annulus (Figure 2). These sutures were later used to secure the annuloplasty ring or band. The posterior leaflet was trimmed to reduce its height to approximately $12 \mathrm{~mm}$, and all remaining secondary chordae tendineae were severed. The false commissures were closed if they were more than $5 \mathrm{~mm}$ deep. Next, starting at the commissural areas and moving centrally, the posterior leaflet was sutured to the endocardium of the left ventricle and displaced annulus with continuous 4-0 polypropylene sutures. This suture line was along the line where the annuloplasty sutures had been placed in the endocardium of the left ventricle, as shown in the lower panel of Figure 2. Excess tissue in the central portion of P2 was resected as needed. Residual prolapse of the posterior leaflet was corrected by creating new chords of 6-0 expanded polytetrafluoroethylene (ePTFE) sutures. The prolapse of the anterior leaflet was corrected by creating numerous new chords of 5-0 ePTFE sutures. A single ePTFE suture was used to create 4 to 6 pairs of chords, as previously described. ${ }^{10}$ Each ePTFE chord was 1 to $2 \mathrm{~mm}$ apart. A rigid annuloplasty ring was used in the first 14 patients, and then a flexible annuloplasty ring was used in the following 30 patients; a flexible posterior band was used in the remaining 139 patients. During the first decade of this study, the selection of size of the annuloplasty ring was based on the intertrigonal distance and area of the anterior leaflet, but as we began to use a posterior band, those measurements served only as an estimate, and the posterior annuloplasty sutures were spaced in the band according to the distance they were spaced in the endocardium of the ventricle. Because most of the posterior leaflet was sutured to the endocardium of the left ventricle, the length of the band along this area was similar to that of the reconstructed annulus because it would be difficult to further reduce the length of the posterior annulus. Four patients required reconstruction of the mitral annulus with an autologous pericardial patch because of extensive annular calcification. ${ }^{11}$ Intraoperative TEE analysis was performed in all patients. No patient left the operating room with more than mild MR or prolapse of any segment. All patients were anticoagulated with warfarin sodium during the first 3 months to maintain an international normalized ratio of 2 to 3 . Oral anticoagulation was discontinued after 3 months unless the patients were in atrial fibrillation or had a thromboembolic event.

\section{Follow-up}

Patients were followed by the referring cardiologist and contacted by our research personnel every other year through a comprehensive questionnaire. They were interviewed by telephone when the patient or the cardiologist reported an adverse event. Echocardiographic studies were performed intraoperatively and before hospital discharge in all patients and at least every second year, either in our institution or by the referring cardiologist, and the results were collected prospectively. The clinical follow-up for this study was closed on September 2007 and was 100\% complete. The mean clinical follow-up time was $5.9 \pm 4.2$ years (range, $1-16$ years). Most patients had multiple echocardiographic studies, and all patients had at least 1 study during the year of follow-up. The mean echocardiographic followup was $5.3 \pm 4.3$ years (range, $1-16$ years).

\section{Statistical Analysis}

All statistical analyses were conducted with SAS Version 9.1 software for Windows (SAS Institute, Inc, Cary, NC). Categorical variables were analyzed by using $\chi^{2}$ analyses or the Fisher's exact test and were expressed as percentages. Continuous variables were expressed as means \pm standard deviation, and means were compared with the Student $t$ test or the Wilcoxon

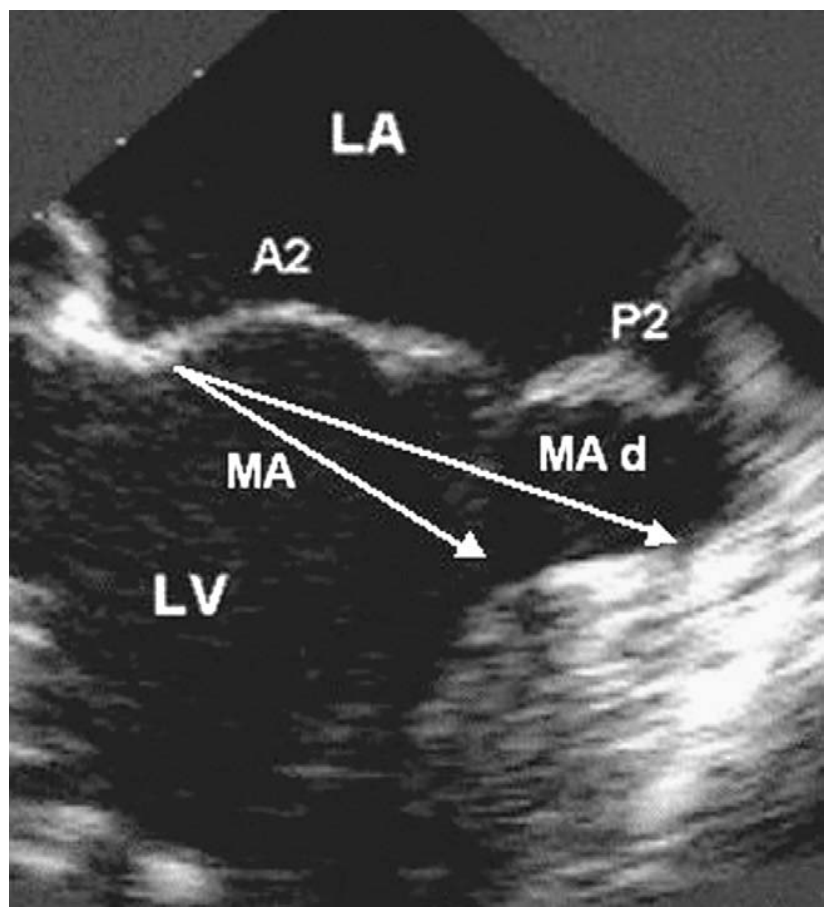

FIGURE 1. Echocardiographic appearance of posterior displacement of the mitral annulus. The arrow marked MA points to where the annulus should be, and the arrow marked $M A d$ points to the displaced annulus. $L A$, Left atrium; $L V$, left ventricle. 
TABLE 1. Clinical profile

\begin{tabular}{lc}
\hline No. of patients & 183 \\
Age (y) & \\
Mean \pm SD & $52 \pm 13$ \\
Range & $22-88$ \\
Sex & \\
$\quad$ Male & $118(64)$ \\
Female & $65(36)$ \\
Marfan syndrome & $9(5)$ \\
Electrocardiogram & \\
Sinus rhythm & $153(84)$ \\
Atrial fibrillation & $29(16)$ \\
Heart block & 1 \\
New York Heart Association functional class & \\
I & $43(24)$ \\
II & $74(40)$ \\
III & $57(31)$ \\
IV & $9(5)$ \\
Left ventricular ejection fraction & \\
$>59 \%$ & $114(62)$ \\
$40 \%$ to 59\% & $62(34)$ \\
$<40 \%$ & $7(4)$ \\
Infective endocarditis & \\
Remote & $8(4)$ \\
Active & 1 \\
Coronary artery disease & $8(4)$ \\
Hypertrophic obstructive cardiomyopathy & $2(1)$ \\
Atrial septal defect & $6(3)$ \\
\hline Va &
\end{tabular}

Values are presented as number (percentage) unless otherwise shown.

rank test. Survival and freedom from morbid events were analyzed by using the Kaplan-Meier method. Cox regression analysis with backward selection was used to identify the multivariable and independent predictors of recurrent MR. The following variables were included: age at the time of the operation in increments of 5 years, sex, left ventricular ejection fraction of less than $40 \%$, New York Heart Association functional class IV, coronary artery disease, 4 or more prolapsed segments, anterior leaflet prolapse, mitral annulus diameter of $46 \mathrm{~mm}$ or greater, posterior displacement of the mitral annulus of $10 \mathrm{~mm}$ or greater, and type of annuloplasty (ring or band). Variable retention in the models was set at a $P$ value of .05 .

\section{Statement of Responsibility}

The authors had full access to the data and take full responsibility for their integrity. All authors have read and agreed to the manuscript as written.

\section{RESULTS}

There were no operative deaths. The postoperative complications were re-exploration of the mediastinum for bleeding in 10 patients, blood transfusion in 62 patients, and atrial fibrillation in 69 patients. There was no perioperative myocardial infarction, stroke, wound infection, renal failure, or any other serious complication. There were 8 late deaths (1 from stroke, 1 from anticoagulation-related hemorrhage, and 6 non-valve- and non-cardiac-related deaths) figure 3 shows the patients' long term survival. At the latest follow-up contact, 170 patients still had their native mitral valve, and $136(80 \%)$ were in functional class I, $23(14 \%)$ were in class II, and $11(6 \%)$ were in class III.
TABLE 2. Perioperative variables

\begin{tabular}{lc}
\hline Preoperative echocardiographic data & \\
Left atrial diameter (mm) & $53 \pm 11$ \\
Mitral annular diameter (mm) & $46 \pm 9$ \\
Posterior displacement of annulus (mm) & $9.4 \pm 3.8$ \\
Prolapsed leaflets & \\
$\quad$ Posterior leaflet & $183(100)$ \\
$\quad$ Anterior leaflet & $126(69)$ \\
No. of prolapsed segments* & \\
1 or 2 & $13(7)$ \\
3 or 4 & $76(41)$ \\
5 or 6 & $94(51)$ \\
Mitral valve repair & \\
Correction of displaced annulus & $183(100)$ \\
Reconstruction of mitral annulus with patch & $4(2)$ \\
Chordal replacement with ePTFE & $170(93)$ \\
Ring/band annuloplasty & \\
$\quad$ Carpentier ring & $12(6)$ \\
$\quad$ Duran ring & $30(16)$ \\
$\quad$ Cosgrove or other posterior band & $141(77)$ \\
Ring/band size (mm) & \\
$\quad \leq 31$ & $9(5)$ \\
32-33 & $31(17)$ \\
34-35 & $34(18)$ \\
36-37 & $38(21)$ \\
Tricuspid valve repair & $71(39)$ \\
Maze procedure for atrial fibrillation & $2(1)$ \\
Coronary artery bypass & $17(9)$ \\
Septal myectomy & $8(4)$ \\
Aatch closure of atrial septal defect & $2(1)$ \\
Cardiopulmonary bypass time (min) & $6(3)$ \\
ICU stay (h) & $76 \pm 19$ \\
Hospital stay (d) & $93 \pm 22$ \\
Vat & $7.4 \pm 6.2$ \\
\hline
\end{tabular}

Values are presented as number (percentage) unless otherwise shown. *P1, P2, P3, A1, A2, and A3 of Carpentier's classification (see Carpentier and colleagues ${ }^{8}$ ).

Six patients required repeat mitral valve operations: 1 rerepair and 5 replacements. All 6 survived. The median time to reoperation was 55 months (range, 9-102 months). The indications for reoperation were severe recurrent MR in 5 patients ( 1 with hemolysis) caused by fibrosis, retraction, and stiffening of at least 1 leaflet in 3 patients; recurrent leaflet prolapse in 2 patients; and mitral stenosis caused by pannus on a Duran annuloplasty ring and leaflets in 1 patient. The freedom from reoperation at 1,5 , and 10 years was $99.4 \% \pm 0.6 \%, 98.7 \% \pm 0.9 \%$, and $92.9 \% \pm 3.0 \%$, respectively.

Fifteen patients had neurologic events: 1 patient died, 3 had permanent deficits, and 11 had transient deficits. Five of those patients had recurrent neurologic events, resulting in 1 permanent deficit and 4 transient deficits. The freedom from thromboembolic complications at 1,5 , and 10 years was $95 \% \pm$ $1.6 \%, 92 \% \pm 2 \%$, and $88 \% \pm 3 \%$, respectively.

There were 6 anticoagulant-related hemorrhage events. One of these was fatal, 2 required blood transfusions, and 

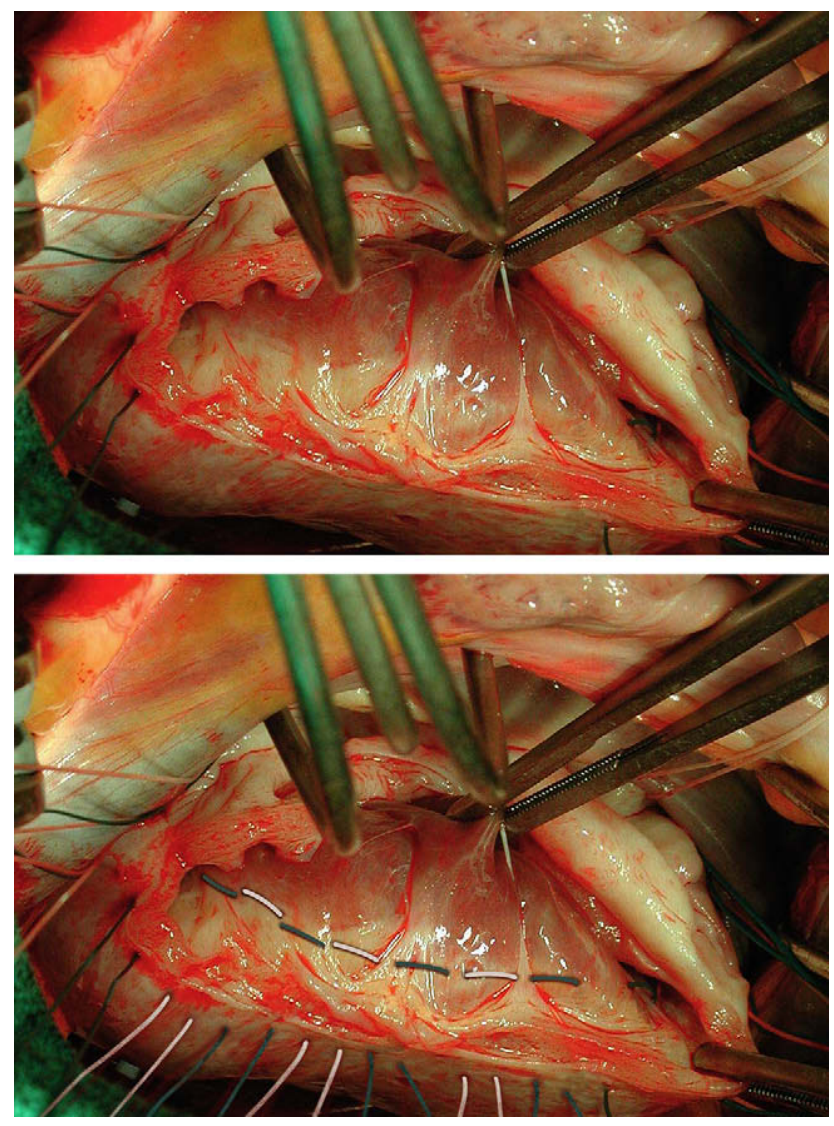

FIGURE 2. Upper panel, Intraoperative photograph of posterior displacement of the mitral annulus. Lower panel, placement of the sutures on the endocardium of the left ventricle and displaced mitral annulus (some sutures were color enhanced for clarity).

3 required no treatment. One of the 6 anticoagulant-related hemorrhages occurred in that first 3-month period. This patient had a good outcome after hospitalization and blood transfusion. The remaining 5 episodes occurred among 31 patients who were taking long-term oral anticoagulation.

Three patients required pacemaker insertion late postoperatively. There were no cases of infective endocarditis and no cases of valve thrombosis. The freedom from valve-related morbidity and mortality at 1,5 , and 10 years was $94 \% \pm$ $2 \%, 90 \% \pm 2 \%$, and $78 \% \pm 4 \%$, respectively, and the event-free survival was $94 \% \pm 1.6 \%, 89 \% \pm 3 \%$, and $75 \% \pm 5 \%$, respectively.

Transthoracic echocardiographic analysis done before hospital discharge showed trace or no MR in 152 patients, mild MR in 29 patients, and mild-to-moderate MR in 3 patients. During the follow-up, 6 patients had severe recurrent MR, and 21 had moderate MR. Among the 32 patients with residual mild MR at hospital discharge, 2 had severe and 4 had moderate MR during follow-up. New York Heart Association functional class IV, prolapse of 4 or more leaflets segments, and annuloplasty band instead of a complete ring were predictors of recurrent moderate or severe MR

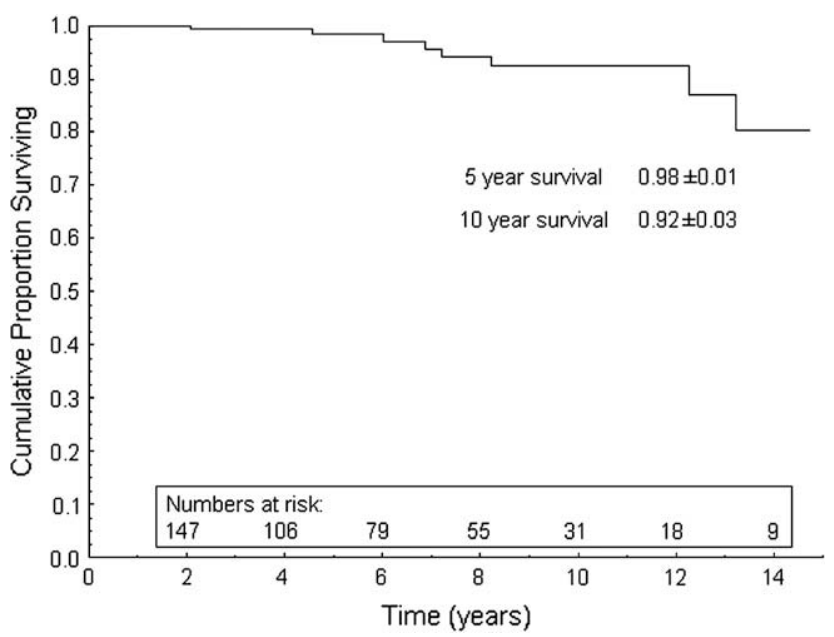

FIGURE 3. Long-term survival of all patients.

by means of univariate analysis, but none of these variables were significant by using Cox regression analysis. Five patients who had severe MR underwent reoperation, and 1 died of cancer. One patient had progressive mitral stenosis caused by excessive pannus on a Duran annuloplasty ring. ${ }^{12}$ Figure 4 shows the freedom from severe MR, and Figure 5 shows the freedom from severe and moderate MR.

The echocardiogram obtained before hospital discharge revealed a mitral valve area of $2.82 \pm 0.81 \mathrm{~cm}^{2}$ and a mean gradient across the valve of $2.3 \pm 1.3 \mathrm{~mm} \mathrm{Hg}$. The mean mitral annulus diameter was $29.2 \pm 5.3 \mathrm{~mm}$ in systole. The left ventricular ejection fraction was normal or minimally impaired in 180 patients and moderately impaired in 3 patients. The left atrial diameter was $43 \pm 8 \mathrm{~mm}$.

At the most recent follow-up, electrocardiographic analysis showed sinus rhythm in 157 (86\%) patients, atrial fibrillation or flutter in $23(12 \%)$ patients, and paced beats in 3 $(2 \%)$ patients.

\section{DISCUSSION}

Since Barlow's initial description of mitral valve prolapse,$^{13}$ there has been much disparity among authors with respect to terminology and the appropriate treatment for various subgroups of patients with degenerative mitral valve disease and MR. Some surgeons use the term Barlow's disease to describe myxomatous degeneration of the mitral valve. ${ }^{14,15}$ However, myxomatous degeneration of the mitral valve has a broad pathologic spectrum, and we prefer to reserve the term Barlow's disease only when there is advanced myxomatous degeneration of the mitral valve, as defined in this article. Several investigators described this entity in terms similar to ours ${ }^{16,17}$ but did not make inferences to the mechanism for the large annuli that are almost invariably associated with this disease. We found a plausible explanation in a seminal study by Hutchins and colleagues. ${ }^{4}$ These investigators postulated that the primary abnormality 


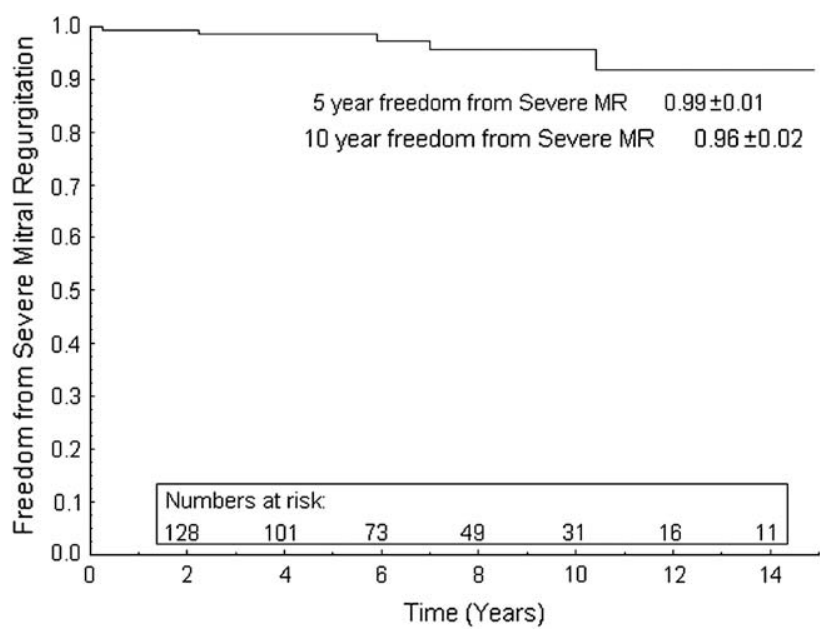

FIGURE 4. Freedom from recurrent severe mitral regurgitation $(M R)$.

was in fact a defect in the annulus fibrosus of the mitral valve, with leaflet deformity occurring as a result of these annular changes. In an autopsy study the authors examined 900 mitral valves and found a variation in the relationship between the mitral annulus, the left atrial wall, and the proximal wall of the left ventricle. There was a subset of 65 with a variant that the authors referred to as "disjunction" of the mitral annulus, where there was wide separation between the annulus and the left ventricular wall. There were 25 patients with myxomatous mitral valves, and of these, there were only 2 who did not exhibit this mitral annular disjunction, but these hearts had ischemic changes to the papillary muscles. ${ }^{4}$ The mechanism of the leaflet changes was postulated to be from hypermobility of the tension apparatus leading to increased mechanical stress on the leaflet tissue, with subsequent thickening and elongation. Angelini and associates $^{18,19}$ countered the interpretation of mitral annular disjunction presented by Hutchins and colleagues. ${ }^{4}$ These

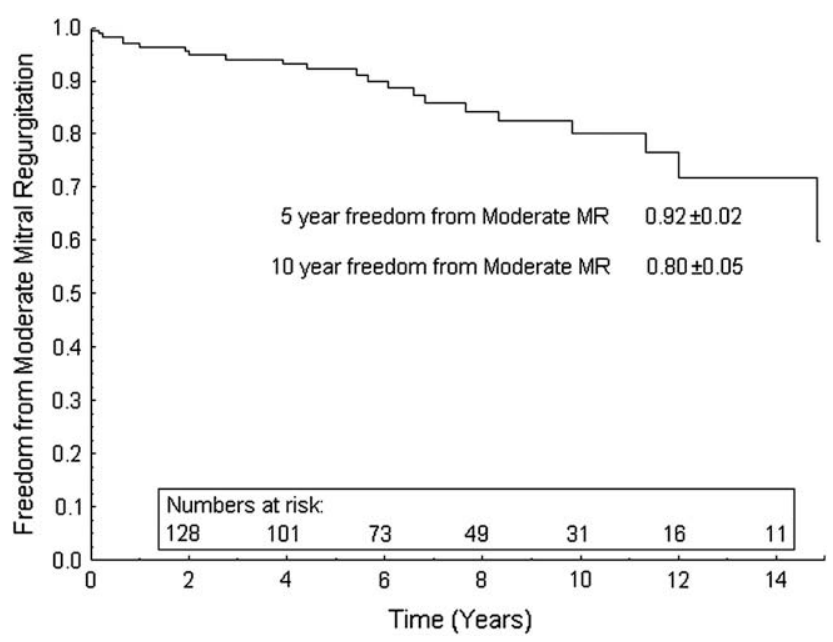

FIGURE 5. Freedom from recurrent moderate or severe mitral regurgitation $(M R)$. authors sectioned the entire mitral annulus of 13 hearts at autopsy and found annular disjunction in 7 hearts without myxomatous changes in the leaflets. ${ }^{18}$ They therefore surmised that annular displacement was a normal anatomic variant and was not responsible for the development of myxomatous mitral valve. Based on our experience, we believe that both groups of investigators were correct. As previously shown, the annulus fibrosus of the mitral valve is not a continuous fibrous structure from the lateral to the medial fibrous trigones in most human subjects. ${ }^{18}$ Myxomatous disease of the mitral valve is a genetically mediated disorder with variable pathologic expression. ${ }^{20}$ Thus the pathologic expression of this genetic disorder is probably more severe in individuals in whom the annulus fibrosus is incomplete, such as in those with posterior displacement of the mitral annulus. This displacement is further accentuated by the increased leaflet volume and consequent increase in tension (LaPlace's law).

The diagnosis of advanced myxomatous degeneration of the mitral valve, as defined in this study, can be easily made by means of echocardiographic, particularly TEE, analysis and confirmed at surgical intervention. ${ }^{5,9}$ Advanced myxomatous degeneration is often a reason mitral valve repair is not feasible in all patients with mitral valve prolapse. ${ }^{15}$ Some patients have thick, fibrotic, and even calcified leaflets, chordae tendineae, and papillary muscles, preventing a good functional result after mitral valve repair. However, as long as the anterior leaflet is pliable and the annulus is not heavily calcified, repair is feasible and the function of the repaired valve is excellent in most patients, as shown in the echocardiographic studies of our patients. The role of the displaced mitral annulus on long-term outcomes of mitral valve repair in these patients is unknown. However, before we were aware of the study by Hutchins and colleagues, ${ }^{4}$ advanced myxomatous degeneration was a predictor of reoperation after mitral valve repair in our experience. ${ }^{21}$ Since then, most patients with advanced myxomatous changes who were referred for surgical intervention have undergone valve repair, and in our hands the probability of repair during the past 2 decades was approximately $87 \%$.

Patients with advanced myxomatous degeneration of the mitral valve are usually younger than patients with isolated prolapse of the posterior leaflet. ${ }^{2}$ The mean age in our series was only 52 years, whereas in a previous report from our institution, the mean age in patients with isolated posterior leaflet prolapse was 60 years. ${ }^{7}$ Consequently, these patients are less likely to have associated cardiovascular and other diseases, and the operative mortality and morbidity are very low. In our series of 183 patients, there was no operative death or serious postoperative complication. Patients with Marfan syndrome who have MR frequently have advanced myxomatous degeneration of the mitral valve. ${ }^{22} \mathrm{Al}-$ though there were only 9 patients with Marfan syndrome in 
our series, we have operated on at least twice as many, but they were not included because they also had aortic root aneurysms and were excluded from this study.

Multiple surgical approaches have been used to repair these valves. ${ }^{14-17,22,23}$ Adams and coworkers ${ }^{16}$ used standard Carpentier techniques combined with large annuloplasty rings. Other groups used the edge-to-edge repair combined with mitral annuloplasty. ${ }^{17,23}$ Flameng and associates ${ }^{15}$ recently compared the results of mitral valve repair of "Barlow disease" with "fibroelastic deficiency." These authors defined Barlow's disease as "myxoid appearance of the whole valve with excess tissue and a dilated annulus" and fibroelastic deficiency as "restriction of thickening to the prolapsed area(s), the remaining valve tissue being more transparent, not thickened, without excess tissue, and the annulus being dilated or not." Barlow's disease was an independent predictor of recurrent MR in their study, and at 10 years, almost one half of the patients had recurrent moderate or severe MR.

None of those reports addressed the issue of posterior displacement of the mitral annulus; however, Flameng and associates ${ }^{15}$ found that "nonuse of sliding plasty" was also a predictor of recurrent MR after mitral valve repair. The significance of posterior displacement of the mitral annulus in mitral valve surgery remains largely unknown but correlates well with the number of prolapsing segments of the leaflets ${ }^{5}$ and with the diameter of the mitral annulus. Displacement of the mitral annulus can be localized to one segment, usually Carpentier's P2 segment, ${ }^{8}$ or as extensive as shown in Figure 2. Early on in our experience with mitral valve repair, advanced myxomatous degeneration emerged as an independent predictor of repair failure. ${ }^{21}$ It was possible that the high failure rate was due to inadequate annuloplasty; that is, the ring or band was secured to the displaced annulus, and the mechanical stresses on the leaflets and chordae were not properly corrected. For this reason, we began to search for alternative operative procedures and came across the study by Hutchins and colleagues ${ }^{4}$ on posterior displacement of the mitral annulus. We have addressed the issue of annular displacement by detaching the posterior leaflet and reattaching it to the endocardium of the proximal ventricular wall and securing an annuloplasty band along the reconstructed area. Because we suture the posterior leaflet and annuloplasty band directly to the endocardium, there is a limit on how much the length of the posterior annulus can be reduced. We believe that reinforcement of the annular reconstruction is vital to the success of this type of repair. Although we favor flexible bands to stabilize the reconstructed posterior annulus, Carpentier and associates ${ }^{24}$ have extensive experience with reattachment of the posterior leaflet to the endocardium of the left ventricle in patients with a calcified annulus and used exclusively rigid rings with excellent results.

Another aspect of our technique of repair that might improve long-term durability is our liberal use of artificial chordae. ${ }^{10}$ We have more than 2 decades of experience with chordal replacement with ePTFE sutures, and initially, we used one 4- 0 suture to create 2 new chords for approximately every centimeter of free margin of leaflet prolapse. By 1995, we began using finer sutures (5-0 and 6-0) and created 3 to 4 pairs of chords for every centimeter of free margin of leaflet prolapse. The pairs were interdependent because they were created with a single suture by successively passing it once through a fibrous portion of the papillary muscle and twice through the free margin of the leaflet, and the ends were tied on the papillary muscle head. ${ }^{10}$ This technique has allowed us to create up to 20 pairs of new chords to anchor all segments of the mitral valve leaflets with relative ease.

This study on the long-term results of mitral valve repair in patients with MR caused by advanced myxomatous degeneration of the mitral valve shows that valve repair is durable but not as durable as for isolated prolapse of the posterior leaflet. ${ }^{7}$ It compares more with outcomes of repair for prolapse of both leaflets or anterior leaflet prolapse. ${ }^{7}$ Actually, most of our patients with advanced myxomatous degeneration of the mitral valve had bileaflet prolapse. The reoperation rate was low because only a few patients had severe recurrent MR. However, a larger number of patients had moderate MR during the follow-up, suggesting that mitral valve repair might slow down but does not arrest the degenerative process. Based on our experience with only 6 reoperations, the main cause of failure was fibrosis and retraction of the mitral valve leaflets. We could not identify predictors of recurrent MR by using a multivariable analysis, likely because of the complexity of this disease and its surgical correction. We might not have adequately assessed all variables that can affect late operative outcomes. Recurrent MR in patients with degenerative disease has been documented by means of echocardiographic analysis by Flameng and associates. ${ }^{15,25}$ Those investigators found that recurrent MR was more common in myxomatous disease than in fibroelastic deficiency. ${ }^{15}$ Thus these patients should be followed with annual echocardiographic studies to assess valve and left ventricular size and function.

\section{Limitations of the Study}

This is a retrospective review of a clinical experience of a single surgeon and is associated with all the shortcomings of this type of study. We did not have a group of patients with similar disease undergoing different techniques to assess the importance of correcting the posterior annular displacement. This report spans over a period of 16 years, and although 1 surgeon performed all operations, the experience in treating these patients must have improved over the years, and it is possible that patients undergoing surgical intervention in recent years will have better outcomes than those who underwent surgical intervention during the early years, particularly during the last decade, when we begin 
to create many more ePTFE chords per prolapsing segment. Finally, because this represents the experience of a single surgeon, the results might not be generalized to all patients with advanced myxomatous degeneration, and other surgeons using different techniques might provide better clinical outcomes.

\section{CONCLUSIONS}

Mitral valve repair for MR caused by advanced myxomatous degeneration of the mitral valve as defined in this study is a complex operative procedure because the mitral annulus is grossly dilated and displaced toward the atrium and the leaflets are thickened and voluminous with prolapse of several segments because of chordal elongation and sometimes papillary muscle fibrosis and elongation. Correction of the annular dilation and posterior displacement, shortening of the height of the posterior leaflet, and prolapse correction provided excellent functional results, but late recurrent MR is common.

\section{References}

1. Carpentier A, Chauvaud S, Fabiani JN, et al. Reconstructive surgery of mitral valve incompetence. Ten-year appraisal. J Thorac Cardiovasc Surg. 1980;79: $338-48$.

2. Filsoufi F, Carpentier A. Principles of reconstructive surgery in degenerative mitral valve disease. Semin Thorac Cardiovasc Surg. 2007;19:103-10.

3. Edwards JE. Pathology of mitral incompetence. In: Silver MD, ed. Cardiovascular pathology. 2nd ed. New York: Churchill Livingstone; 1991. p. 961-84.

4. Hutchins GM, Moore GW, Skoog DK. The association of floppy mitral valve with disjunction of the mitral annulus fibrosus. N Engl J Med. 1986;314:535-40.

5. Eriksson MJ, Bitkover CY, Omran AS, et al. Mitral annular disjunction in advanced myxomatous mitral valve disease: echocardiographic detection and surgical correction. J Am Soc Echocardiogr. 2005;18:1014-22.

6. Barlow JB, Bosman CK. Aneurysmal protrusion of the posterior leaflet of the mitral valve. An auscultatory-electrocardiographic syndrome. Am Heart J. 1966;71:166-78.

7. David TE, Ivanov J, Armstrong S, Christie D, Rakowski H. A comparison of outcomes of mitral valve repair for degenerative disease with posterior, anterior, and bileaflet prolapse. J Thorac Cardiovasc Surg. 2005;130:1242-9.
8. Carpentier AF, Lessana A, Relland JY, et al. The "physio-ring": an advanced concept in mitral valve annuloplasty. Ann Thorac Surg. 1995;60:1177-85.

9. Omran AS, Woo A, David TE, Feindel CM, Rakowski H, Siu SC. Intraoperative transesophageal echocardiography accurately predicts mitral valve anatomy and suitability for repair. J Am Soc Echocardiogr. 2002;15:950-7.

10. David TE. Artificial chordae. Semin Thorac Cardiovasc Surg. 2004;16:161-8.

11. David TE, Feindel CM, Armstrong S, Sun Z. Reconstruction of the mitral annulus: a ten year experience. J Thorac Cardiovasc Surg. 1995;110:1323-32.

12. Ibrahim MF, David TE. Mitral stenosis after mitral valve repair for non-rheumatic mitral regurgitation. Ann Thorac Surg. 2002;73:34-6.

13. Barlow JB, Pocock WA. The significance of late systolic murmurs and mid-late systolic clicks. Md State Med J. 1963;12:76-7.

14. Dreyfus GD, Souza Neto O, Aubert S. Papillary muscle repositioning for repair of anterior leaflet prolapse caused by chordal elongation. J Thorac Cardiovasc Surg. 2006; 132:578-84.

15. Flameng W, Meuris B, Herijers P, Herregods MC. Durability of mitral valve repair in Barlow disease versus fibroelastic deficiency. $J$ Thorac Cardiovasc Surg. 2008;135:274-82.

16. Adams DH, Anyanwu AC, Rahmanian PB, Abascal V, Salzberg SP, Filsoufi F. Large annuloplasty rings facilitate mitral valve repair in Barlow's disease. Ann Thorac Surg. 2006;82:2096-100.

17. Lapenna E, Torracca L, De Bonis M, La Canna G, Crescenzi G, Alfieri O Minimally invasive mitral valve repair in the context of Barlow's disease. Ann Thorac Surg. 2005;79:1496-9.

18. Angelini A, Ho SY, Anderson RH, Davies MJ, Becker AE. A histological study of the atrioventricular junction in hearts with normal and prolapsed leaflets of the mitral valve. Br Heart J. 1988;59:712-6.

19. Angelini A, Ho SY, Anderson RH, Becker AE, Davies MJ. Disjunction of the mitral annulus in floppy mitral valve. N Engl J Med. 1988;318:188-9.

20. Kyndt F, Gueffet JP, Probst V, et al. Mutations in the gene encoding filamin A as a cause for familial cardiac valvular dystrophy. Circulation. 2007;115:40-9.

21. David TE, Armstrong S, Sun Z, Daniel L. Late results of mitral valve repair of mitral regurgitation due to degenerative disease. Ann Thorac Surg. 1993; 56:7-14.

22. Fuzellier JFG, Chauvaud SM, Fornes P, et al. Surgical management of mitral regurgitation associated with Marfan's syndrome. Ann Thorac Surg. 1998;66: 68-72.

23. Oc M, Doukas G, Alexiou C, Oc B, Hadjinikolaou L, Sosnowski AW, Spyt TJ Edge-to-edge repair with mitral annuloplasty for Barlow's disease. Ann Thorac Surg. 2005;80:1315-8.

24. Carpentier AF, Pellerin M, Fuzellier JG, Relland JYM. Extensive calcification of the mitral valve annulus. Pathology and surgical treatment. J Thorac Cardiovasc Surg. 1996;111:718-30.

25. Flameng W, Herijgers P, Bogaerts K. Recurrence of mitral valve regurgitation after mitral valve repair in degenerative valve disease. Circulation. 2003;107: 1609-13. 